\title{
Patrimonio concurrente. La necesidad de la gestión conjunta en el patrimonio arqueológico en la provincia de Cádiz
}

\author{
Ana Mateos Orozco | Personal Investigador en Formación Universidad de Sevilla \\ URL de la contribución <http://www.iaph.es/revistaph/index.php/revistaph/article/view/4387>
}

Las agendas urbanas de Andalucía buscan conseguir un trabajo comunal que garantice políticas culturales conjuntas a nivel territorial. Entre sus líneas estratégicas con el objetivo de lograr ciudades sostenibles e integradas, se propone una mejora en el patrimonio urbano y territorial, promoviendo un mayor equilibrio territorial y garantizando la cultura y protección de cualquier tipo de patrimonio.

En mi trabajo fin de Máster en Arquitectura y Patrimonio Histórico abordé diferentes poblaciones de la provincia de Cádiz que protagonizaron o pudieron tener cierta participación en la conquista islámica de la Península Ibérica o en los primeros años de la consolidación de al Andalus. No solo eran de interés los núcleos poblacionales, también yacimientos arqueológicos o elementos patrimoniales de su entorno de enorme relevancia para el periodo altomedieval. Estos elementos se analizaron en términos de estudio, conservación y protección, con el objetivo de valorar su situación actual, y comparar estos datos con la percepción que tienen sus poblaciones.

El resultado no fue el esperado, la mayoría de estos elementos patrimoniales, a pesar de encontrarse protegidos legalmente, no cuentan con verdaderas medidas de conservación. Además, muchos de ellos no se han vuelto a estudiar desde su descubrimiento o desde su inclusión en el catálogo correspondiente, llevándolos al olvido o desconocimiento. Debemos añadir que además no existe uniformidad en el tipo de protección y gestión de dichos elementos patrimoniales. Todo esto complejiza que estos elementos puedan entenderse como un unicum, perteneciendo a momentos cronológicamente afines y con significados comunes que deberían asumirse en conjunto y no como elementos aislados.

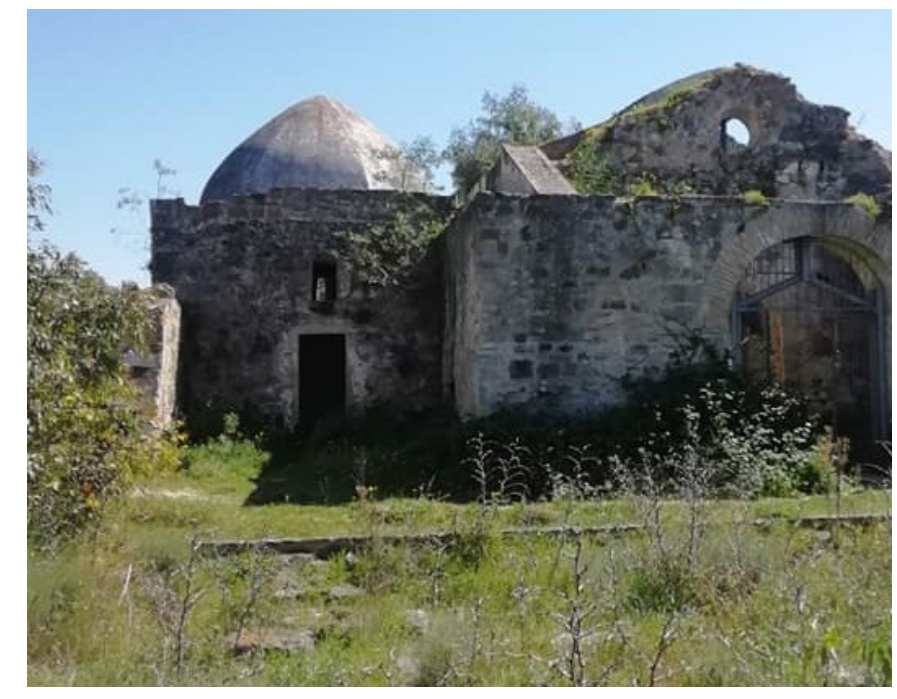

Ermita de San Ambrosio (Barbate) | foto Ana Mateos Orozco

No existe para la provincia de Cádiz un plan conjunto y común para la gestión patrimonial, generando enormes diferencias entre ciudades que podrían tener las mismas posibilidades y potencial. Encontramos enormes disparidades entre lugares muy cercanos y con similitudes, un ejemplo de esto podrían ser Vejer de la Frontera y Alcalá de los Gazules. A pesar de las evidentes diferencias, ambas comparten elementos básicos como su entramado urbano, historia, etc. Sin embargo, sus estrategias culturales y patrimoniales difieren enormemente, y encontramos en Vejer de la Frontera uno de los focos culturales y turísticos de la provincia, mientras que Alcalá, a pesar de su enorme riqueza patrimonial, no cuenta con la misma situación. Esto no es solo un problema a nivel turístico y económico, sino que a nivel poblacional hemos podido detectar que la población de Alcalá de los Gazules conoce muy poco la historia de su población, y que en aquellos casos que sí lo hacen suelen asociarla con leyendas, cuentos o histo- 
a debate El papel del patrimonio en las nuevas políticas para la cultura, la ciudad y el territorio: las agendas urbanas como marco de oportunidad

| coordinan Blanca del Espino Hidalgo, Rafael Merinero Rodríguez

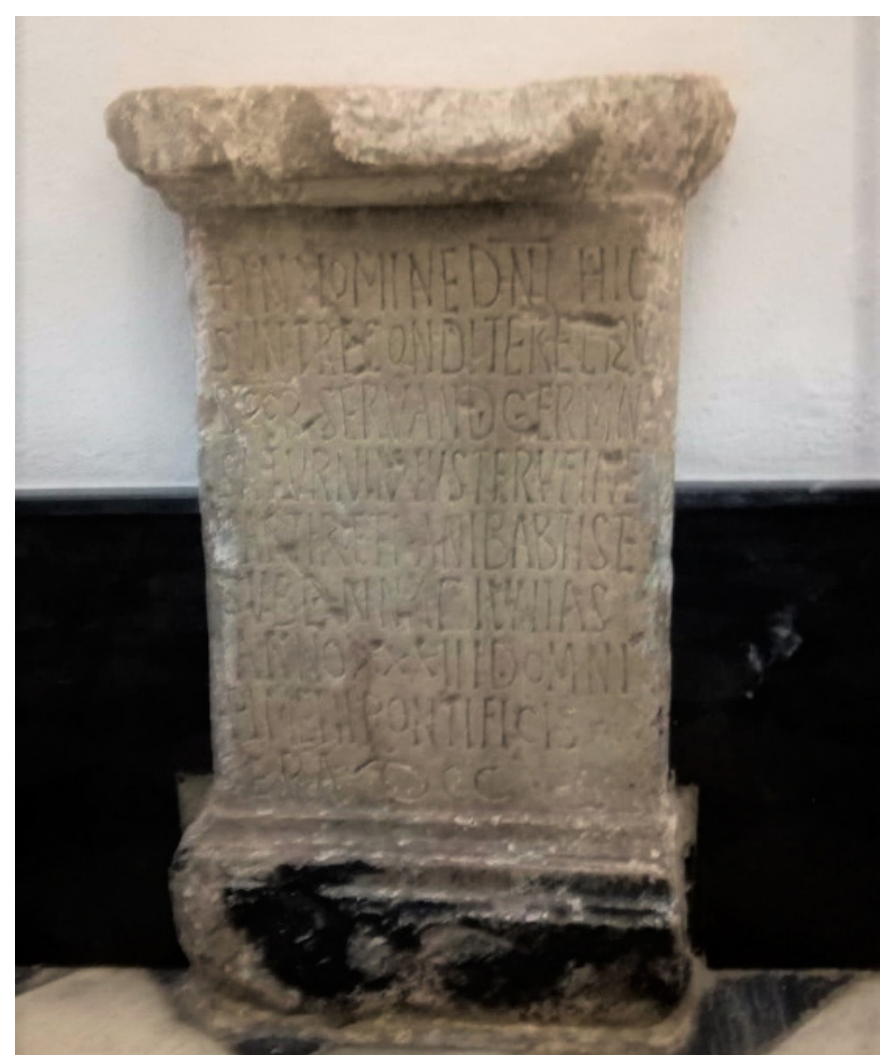

Pedestal visigodo de la basílica de Alcalá de los Gazules, actualmente en la Iglesia de San Jorge (Alcalá de los Gazules) | foto Ana Mateos Orozco

rias de tradición oral. El desarraigo y la no identificación de las poblaciones con su propio patrimonio conduce a que este no se valore ni se proteja.

Comparando la protección y gestión de la que gozan o no los diferentes elementos patrimoniales, comprobamos que en su mayoría se asocian al municipio del que dependen, a pesar de que sean parte de un "sistema patrimonial territorial", es decir, un paisaje o territorio en el que los elementos se relacionan de manera integradora teniendo en cuenta diferentes patrimonios (FERIA TORIBIO, 2013: 4-6). Un ejemplo es la Ermita de la Oliva (Vejer de la Frontera) en cuyo interior se encuentran diversos epígrafes cristianos del siglo VII, pertenecientes a la Ermita de San Ambrosio, en Barbate. Al mismo tiempo, en Medina Sidonia y en Alcalá encontramos otros pedestales similares y que relacionan todas estas poblaciones de manera directa, los centros de culto más importantes en época visigoda (GARCÍA VARGAS; ORIA SEGURA, 2017: 120-125). Podríamos considerar este fenómeno un "sistema patrimonial" o "paisaje patrimonial", pero la realidad es que, al encontrarse estos elementos disociados, la población no es consciente de su estrecha relación.

La aplicación de la agenda urbana en la provincia de Cádiz supondría sin duda un mejor desarrollo de las poblaciones que se anexionen a las mismas. Aunque estas sean de carácter voluntario, aportan beneficios notables sin necesidad de suponer o tomar grandes riesgos en su práctica. Las poblaciones que han decido poner en práctica las agendas urbanas, no lo han hecho de manera conjunta, restando ineficacia a nivel territorial. Además, muchas poblaciones de menor tamaño no se integran en las agendas al no ser ciudades y tampoco deciden tomar la iniciativa junto a una población cercana de mayor envergadura. En la provincia se marcan tres grandes zonas de interés: Bahía de Cádiz y su zona metropolitana, zona de la Serranía de Cádiz y Bahía de Algeciras, quedando como señalábamos zonas fuera de esta planificación que no llegan a encajar con estos entornos y que son, principalmente, paisajes agrarios y territorios rurales. Anterior a las agendas urbanas, se promovieron los fondos EDUSI; sin embargo, estos solo fueron concedidos a la zona metropolitana de la Bahía de Cádiz, estaban de nuevo a la espalda de este proyecto, y sin conseguir los fondos, el litoral sur (encabezado por Barbate, Vejer de la Frontera y Tarifa) y la Sierra de Cádiz (Pueblos Blancos).

Como podemos comprobar, existen zonas en la provincia que necesitan dinamizarse y reactivarse. Las agendas urbanas no solo pueden ser el método para lograr eliminar este desequilibrio regional, sino que además pueden garantizar un trabajo conjunto, mucho más efectivo y ambicioso. Romper con el desequilibrio supondría además garantizar sostenibilidad en términos de patrimonio, turismo y economía, liberando a las zonas de mayor flujo turístico y activando aquellas donde este apenas tiene lugar. En este tipo de idea no tiene cabida el 
_a debate El papel del patrimonio en las nuevas políticas para la cultura, la ciudad y el territorio: las agendas urbanas como marco de oportunidad

| coordinan Blanca del Espino Hidalgo, Rafael Merinero Rodríguez

denominado "turismo de masas", sino uno que garantice calidad y atienda a las necesidades locales (TROITIÑO VINUESA; TROITIÑO TORRALBA, 2018: 215).

\section{BIBLIOGRAFÍA}

- AgENDA Urbana de Andalucía. Acuerdo de 18 de septiembre de 2018, del Consejo de Gobierno, por el que se aprueba la Agenda Urbana de Andalucía. Boletín Oficial de la Junta de Andalucía, n. ${ }^{\circ}$ 185, lunes 24 de septiembre de 2018 <https://juntadeandalucia.es/boja/2018/185/BOJA18-18500002-15362-01_00142635.pdf> [Consulta: 29/04/2019]

- GARCÍA VARGAS, E.; ORIA SEGURA, M. (2017) Baesippo y su territorio en época romana. En FERRER ALBELDA, E.; CANTILLO DUARTE, J. J. (coord.) Arqueología en Vejer. De la Protohistoria al Período Andalusí. Sevilla: Universidad de Sevilla y Ayuntamiento de Vejer, 2017, pp. 95-139

- FERIA TORIBIO (2013) El patrimonio territorial: algunas aportaciones para su entendimiento y puesta en valor. E-rph. Revista electrónica de patrimonio histórico [en línea], n. ${ }^{\circ} 12$, 2013, pp. 1-25 <http://revistaseug.ugr.es/index.php/erph/ article/view/3483> [Consulta: 07/05/2019]

- TROITIÑO VINUESA; TROITIÑO TORRALBA (2018) Visión territorial del patrimonio y sostenibilidad del turismo. Boletín de la Asociación de Geógrafos Españoles, n. ${ }^{\circ} 78,2018$, pp. 212244 